\title{
Effect of knee positions on cardiac compression variables in cardiopulmonary resuscitation of rescuer; Manikin study
}

\author{
Seung-Hyun Hyun', Jong-Hee Han², Che-Cheong Ryew ${ }^{1, *}$ \\ 'Department of Kinesiology, College of Natural Science, Jeju National University, Jeju, Korea \\ Jeju Branch, Korea Lifesaving Association, Jeju, Korea
}

The aim of the study was to analyze the effect of knee positions on cardiac compression variables in cardiopulmonary resuscitation (CPR) using the manikin. Adult with career of CPR instructor $(n=9$; mean age, $27.11 \pm 6.60$ years; mean heights, $177.39 \pm 4.40 \mathrm{~cm}$; mean weights, $69.45 \pm 14.85 \mathrm{~kg}$ ) participated in the experiment, and each participant performed cardiac compression from two different knee positions. Cardiac compression was 30 times per minute for each position with order of position randomized. The results obtained from variables of cardiac compression force were composed of compression velocity, elapsed time, decay rate, and loading rate in maximum and minimum medial-lateral, anterior-posterior (AP), vertical direction respectively. The above variables in $20.3 \mathrm{~cm}$ of knee position showed effective result than that of $50 \mathrm{~cm}$ of knee position, while maximum AP compression force increased. Given the often predictable setting of sports and exercise rehabilitation related with cardiac arrest, CPR relative to change of knee position were significantly associated with more efficient cardiac compression variables. These data have significant implications for health services program in fields of sports and exercise rehabilitation.

Keywords: Cardiac compression, Knee position, Manikin, Loading rate, Decay rate

\section{INTRODUCTION}

Although regular physical activity benefits cardiovascular health (Paffenbarger et al., 1993) sport, particularly when practiced vigorously, has been frequently shown to increase the risk of dying suddenly during or shortly after exercise (Albert et al., 2000; Siscovick et al., 1984). Against the miserable results like unexpected sports-related sudden death, the recent availability of the public giving access to defibrillation is obligated to mandate a thorough understanding of this phenomenon across the public population (Capucci et al., 2002; Rea and Page, 2010).

In spite of progressive development in cardiopulmonary resuscitation (CPR), the number of death by unexpected cardiac arrest increased gradually. Therefore clinic experts on the basis of scientific background recommended the compression depth of about 4 $\mathrm{cm}, 4-5 \mathrm{~cm}$, and $5 \mathrm{~cm}$ within velocity of 100-120 times per minute as order of an infant, young child, and adult respectively as revised guideline manual of compression depth and velocity for improvement of vital possibility for the cardiac arrest (Idris et al., 2012; Stiell et al., 2014). But autopsy against died patient after CPR disclosed fractured rib (13\%-97\%) and sternum (1\%-43\%) and pneumothorax, hemothorax, pulmonary contusion, liver laceration, fat embolism, splenic injury etc. frequently (Hellevuo et al., 2013).

Therefore chest compression should be performed on the accurate depth and velocity in vertical up-down direction and minimized asymmetric compression forward diagonal direction for decrease the risk of rib's fracture. The CPR guidelines recommend that the rescuer's arms should be straight, their shoulders positioned directly over the hand, and hip joints used as a fulcrum, so
${ }^{*}$ Corresponding author: Che-Cheong Ryew (iD https://orcid.org/0000-0001-9473-3990 Department of Kinesiology, College of Natural Science, Jeju National University, 102 Jejudaehak-ro, Jeju 63243, Korea

Tel: +82-64-754-3588, Fax: +82-64-757-1752, E-mail: ryew@jejunu.ac.kr

Received: March 26, 2018 / Accepted: May 3, 2018
This is an Open Access article distributed under the terms of the Creative Commons Attribution Non-Commercial License (http://creativecommons.org/licenses/by-nc/4.0/) which permits unrestricted non-commercial use, distribution, and reproduction in any medium, provided the original work is properly cited. 
that the thrust of each external chest compression is straight down onto the sternum (Guidelines for cardiopulmonary resuscitation and emergency cardiac care, 1992).

Rescuer should maintain on bended knees position for not only carrying out chest compression for long time but also maximizing of compression time and minimizing of lumbar pain, but CPR could be performed on various positions according to rescue situation (Foo et al., 2010). That is, quantitative and quality of CPR depends upon knee position rescuer (Chi et al., 2008), but yet quantitative data related with proper position of knee.

Adequate CPR not only creates blood flow delivering oxygen to the brain and myocardium but also increases the effectiveness of shock in patients with ventricular fibrillation (Cobb et al., 1999; Stiell et al., 2003; Wik et al., 2003). However, prevention and prediction of exercise-related cardiac arrest turns out to be difficult. Regular CPR practice on cardiac arrest patient in sports activity and daily life can prevent a sudden death and provide effective and positive guideline to those who is necessary an exercise rehabilitation.

Particularly, because of high frequency of cardiac arrest in various activity (Albert et al., 2000; Marijon et al., 2011; Paffenbarger et al., 1993; Siscovick et al., 1984), It is necessary for employee of sports and exercise rehabilitation to understand accurately on $\mathrm{CPR}$ characteristics and elevate the vitality and $\mathrm{CPR}$ practice trial $(\%)$ in situation of various cardiac arrest occurrence. Therefore the aim of the study is to analyze an effect on the chest compression force-related variables relative to positions of knee of rescuer.

\section{MATERIALS AND METHODS}

\section{Subject}

Participants was consisted of adult with career of CPR instructor $(\mathrm{n}=9$; mean age, $27.11 \pm 6.60$ years; mean height, $177.39 \pm$ $4.40 \mathrm{~cm}$; mean weight, $69.45 \pm 14.85 \mathrm{~kg}$ ). The subjects who consented on the preliminary detail explanation on the management of individual information, experimental procedure and method etc. participated in the experiment.

\section{Experimental procedure}

Because the situations of cardiac arrest can occurs daily life at home, job, public square, various situations in addition to hospitals, practiced trials without pre-exercise at interval of every 10 min per after one's experimental consent. Each trial was practiced randomly at 2 types of distance of $23.3 \pm 3.2 \mathrm{~cm}$ (each preference distance) and $50 \mathrm{~cm}$ between chest compression point and knee and measurement of each distance was recorded at real time (Fig. 1). And then chest compression was performed in a situation positioned practical manikin (Little Anne QCPR, Laerdal, Norway) on ground reaction force (AMTI-OR-7, Advanced Mechanical Technology Inc., Watertown, MA, USA) and with $1,000 \mathrm{~Hz}$ of sample rate.

Each participants performed 30 times $\times 5$ set of chest compres-

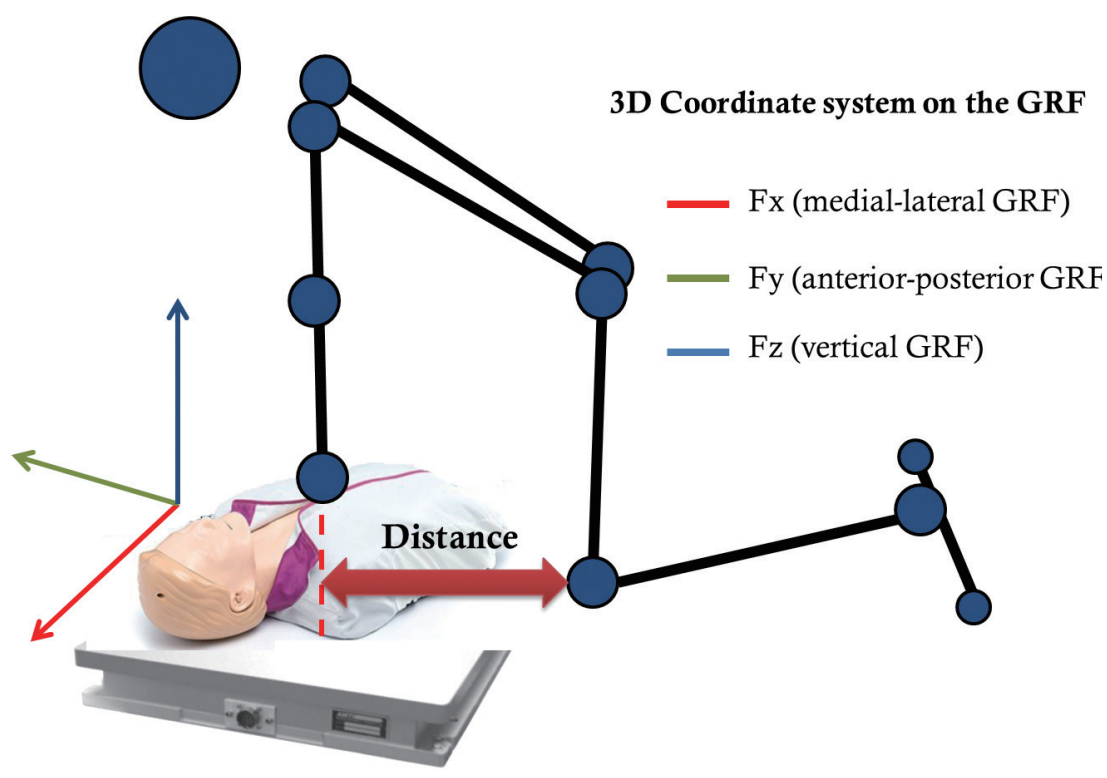

Fig. 1. Distance between compression point and knee joint. 3D, 3-dimensional; GRF, ground reaction force. 
sion, and collected on monitoring to PC using Kwon GRF 2.0 (Visol, Gwangmyeong, Korea). And then 3 dimensional coordinates on ground reaction force was set up as (Fig. 1).

\section{Definition of analysis phase}

Variables of cardiac compression force were composed of compression velocity, elapsed time, maximum and minimum medial-lateral, anterior-posterior, vertical direction, decay rate, and loading rate (Fig. 2).

Cardiac compression velocity (CCV) calculated as a follow. Where TT is the total elapsed time during compression, and NR as the number of repetition to cardiac compression.

$$
\mathrm{CCV}=60 \mathrm{sec} / \mathrm{TT} \times \mathrm{NR}
$$

Then TT and NR mean total time and number of repetition (30 times).

Cardiac compression rate $=$ peak vertical compression force $-\mathrm{VFO} / \Delta \mathrm{t}$ Cardiac compression decay rate $=$ VFO $-\mathrm{PVC}$ force $/ \Delta \mathrm{t}$ Here PVC means peak vertical compression force.
VFO means minimum value before peak vertical force occurrence.

$\Delta \mathrm{t}$ means elapsed time during the phase.

\section{Analysis and process of data}

The average and the standard deviation of the calculated variables were obtained using IBM SPSS Statistics ver. 21.0 (IBM Co., Armonk, NY, USA), and paired $t$-test for comparisons between two knee position $(P<0.05)$.

\section{RESULTS}

Analyzed result of compression force variables according to knee position was as (Table 1). Knee position of $50 \mathrm{~cm}$ in compression velocity and elapsed time showed the faster than that of knee position of $23.3 \mathrm{~cm}$. In minimum cardiac compression analyzed, position of $50 \mathrm{~cm}$ in medial-lateral, anterior-posterior, and vertical compression force showed higher force than that of knee
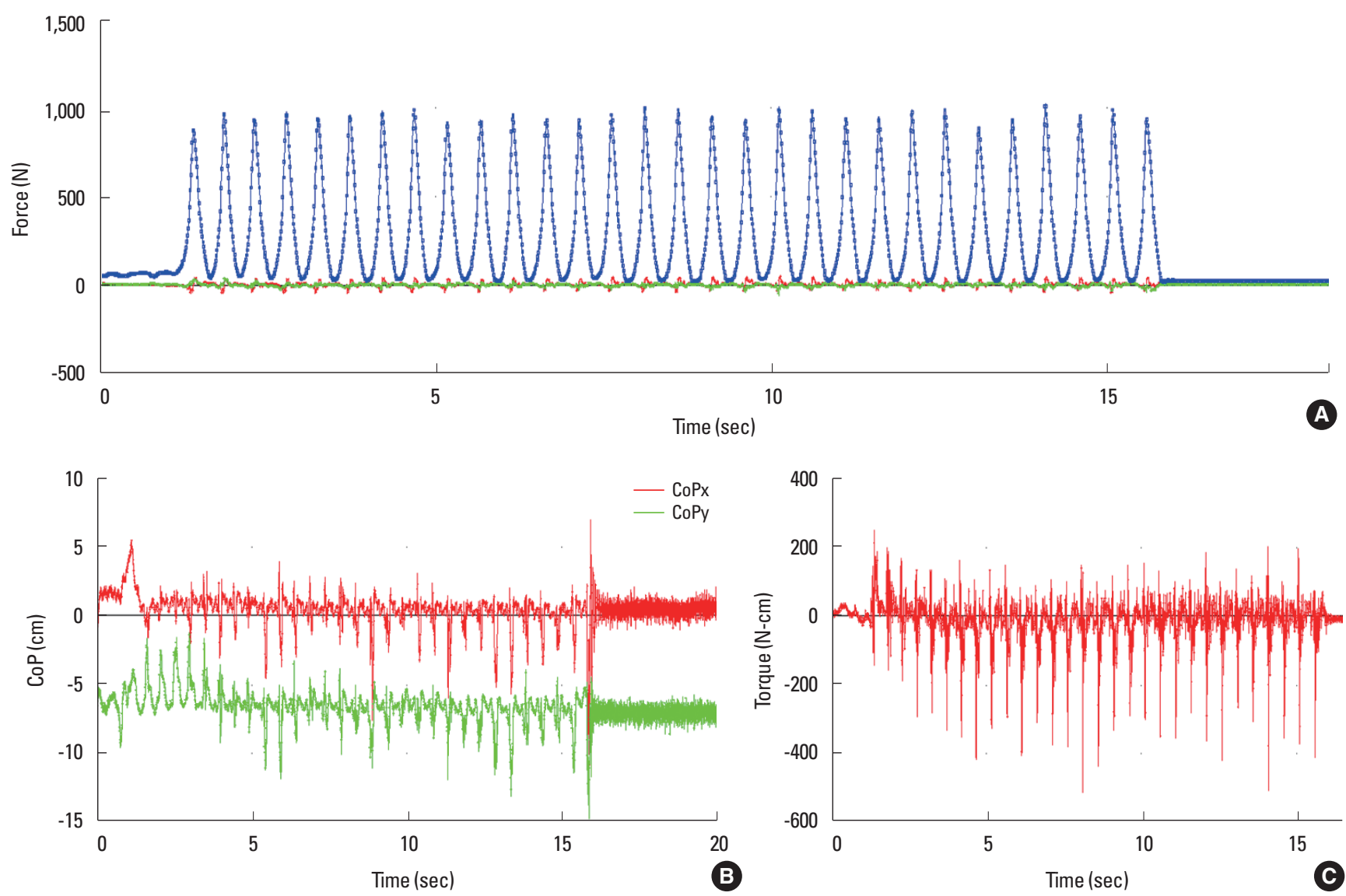

Fig. 2. Pattern of the ground reaction force during cardiac compression. (A) Red, medial-lateral force; green, anterior-posterior force; blue, vertical force. (B) Red, medial-lateral center of pressure (CoP); green, anterior-posterior center of pressure. (C) Torque. 
Hyun SH, et al. • Ground reaction force analysis on the cardiac compression

Table 1. Change of cardiac compression force variables according to the knee positions during 30 times cardiac compression

\begin{tabular}{|c|c|c|c|c|c|}
\hline \multirow{2}{*}{ Section } & \multirow{2}{*}{ Cardiac compression force variables } & \multicolumn{2}{|c|}{ Distance between cardiac compression point and knee joint } & \multirow{2}{*}{$t$} & \multirow{2}{*}{$P$-value } \\
\hline & & $23.3 \pm 3.2 \mathrm{~cm}$ & $50 \mathrm{~cm}$ & & \\
\hline \multirow[t]{2}{*}{ Total } & Velocity (times/min) & $120.31 \pm 3.10$ & $127.54 \pm 8.30$ & 2.446 & $0.026^{*}$ \\
\hline & Elapsed time (sec) & $14.97 \pm 0.39$ & $14.16 \pm 0.92$ & 2.396 & $0.029^{*}$ \\
\hline \multirow[t]{4}{*}{ Minimum compression } & Average medial-lateral compression force (N) & $-2.30 \pm 10.68$ & $-12.49 \pm 32.62$ & 4.958 & $<0.001^{* * *}$ \\
\hline & Average anterior-posterior compression force (N) & $2.40 \pm 11.41$ & $13.35 \pm 33.16$ & 5.125 & $<0.001^{* * *}$ \\
\hline & Average vertical compression force (N) & $37.45 \pm 17.24$ & $75.04 \pm 57.89$ & 10.401 & $<0.001^{* * *}$ \\
\hline & Average compression decay rate ( $\mathrm{N} / \mathrm{sec})$ & $-3,246.36 \pm 586.67$ & $-2,800.54 \pm 463.30$ & 9.799 & $<0.001^{* * *}$ \\
\hline \multirow[t]{4}{*}{ Maximum compression } & Average medial-lateral compression force (N) & $4.434 \pm 14.32$ & $-13.40 \pm 32.80$ & 8.147 & $<0.001^{* * *}$ \\
\hline & Average anterior-posterior compression force (N) & $-47.91 \pm 35.77$ & $-6.63 \pm 70.69$ & 8.560 & $<0.001^{* * *}$ \\
\hline & Average vertical compression force (N) & $768.36 \pm 91.98$ & $687.47 \pm 68.22$ & 11.607 & $<0.001^{* * *}$ \\
\hline & Average compression loading rate $(\mathrm{N} / \mathrm{sec})$ & $2,833.51 \pm 544.40$ & $1,642.24 \pm 548.52$ & 4.067 & $<0.001^{* * *}$ \\
\hline
\end{tabular}

Values are presented as mean \pm standard deviation.

${ }^{*} P<0.05 .{ }^{* * *} P<0.001$.

position of $23.3 \mathrm{~cm}$, while compression decay rate decreased.

In maximum cardiac compression analyzed, knee position of $23.3 \mathrm{~cm}$ in anterior-posterior, vertical compression force, and compression loading rate showed higher force than that of knee position of $50 \mathrm{~cm}$, while medial-lateral compression force decreased.

\section{DISCUSSION}

A meta-analysis of 22 randomized trials of exercise-based rehabilitation after myocardial infarction in 4,554 patients showed a $20 \%$ to $25 \%$ reduction both in overall mortality and in cardiovascular mortality (O'Connor et al., 1989). Similarly, a meta-analysis of 10 trials in 4,347 patients showed that comprehensive rehabilitation had a beneficial effect on mortality, but not on the rate of recurrent myocardial infarction (Oldridge et al., 1988).

Cardiac arrest may result in high mortality by occurring or reoccurring on cardiac patient and normal person, but be improve quality of life with exercise rehabilitation program (Gassner et al., 2003). Above all, at occurring of cardiac arrest, proactive trial of $\mathrm{CPR}$ is very important, therefore proficient performer must more execute and understand accurately than that of CPR guideline manual on the mechanism of chest compression force particularly in case of a profession because cardiac arrest situation may be generated frequently in sport activity and exercise rehabilitation.

Considering various cardiac arrest situation, the analyzed result of chest compression variables in 2 types of chest compression point and knee position showed similar pattern with compression velocity (100-120 times/min) suggested in CPR guideline manual in case of $23.3 \mathrm{~cm}$ of knee position and elapsed chest compres- sion time of 1 cycle on 30 times was near $14.97 \mathrm{sec}$.

The higher vitality in case of performing at accurate depth during chest compression reported (Hostler et al., 2011; Stiell et al., 2012; Stiell et al., 2014; Vadeboncoeur et al., 2014), and chest compression force maintained at the higher, faster level and relaxing force in $23.3 \mathrm{~cm}$ than that of $50 \mathrm{~cm}$ of knee position of this study.

While every the next chest compression must perform sufficiently to flow blood towered heart (Glatz et al., 2013; Zuercher et al., 2010), insufficient chest relaxation can result in increase of inner thorax pressure and decrease of cardiac output, and it can decrease blood of coronary and cerebral arteries (Yannopoulos et al., 2005; Zuercher et al., 2010).

That is, accurate chest compression force and relaxation must be forced to cardiac arrest patient, and these mechanism be corresponded with compression load rate and decrease rate of this study. Compression load rate and decrease rate can define as velocity of minimum and maximum compression force toward cardiac arrest patient. These variables of this study maintained $768 \mathrm{~N}$ of mean chest compression force and considered to be core factors that can reduce the shearing compression of anterior-posterior against medial-lateral. In contrast to the above, considering compression force against anterior-posterior showed more value in $23.3 \mathrm{~cm}$, it is necessary to analyze with more specified distance between compression point and knee position to minimize the asymmetric compression force.

Thus the study suggested that 23.3-cm distance between chest compression point and knee position can maintain higher chest compression force and effective relaxation than that of the other though rescuer performs at various positions at cardiac arrest pa- 
tient. The next study will be necessary to analyze the relation with not only chest compression depth of hand segment against vertical direction in 3 dimension but also application of various treatment level in anterior-posterior direction for more accurate investigation of chest compression force

\section{CONFLICT OF INTEREST}

No potential conflict of interest relevant to this article was reported.

\section{REFERENCES}

Albert CM, Mittleman MA, Chae CU, Lee IM, Hennekens CH, Manson JE. Triggering of sudden death from cardiac causes by vigorous exertion. N Engl J Med 2000;343:1355-1361.

Capucci A, Aschieri D, Piepoli MF, Bardy GH, Iconomu E, Arvedi M. Tripling survival from sudden cardiac arrest via early defibrillation without traditional education in cardiopulmonary resuscitation. Circulation 2002;106:1065-1070.

Chi CH, Tsou JY, Su FC. Effects of rescuer position on the kinematics of cardiopulmonary resuscitation (CPR) and the force of delivered compressions. Resuscitation 2008;76:69-75.

Cobb LA, Fahrenbruch CE, Walsh TR, Copass MK, Olsufka M, Breskin M,

Hallstrom AP. Influence of cardiopulmonary resuscitation prior to defibrillation in patients with out-of-hospital ventricular fibrillation. JAMA 1999;281:1182-1188.

Foo NP, Chang JH, Lin HJ, Guo HR. Rescuer fatigue and cardiopulmonary resuscitation positions: a randomized controlled crossover trial. Resuscitation 2010;81:579-584.

Gassner LA, Dunn S, Piller N. Aerobic exercise and the post myocardial infarction patient: a review of the literature. Heart Lung 2003;32:258265.

Glatz AC, Nishisaki A, Niles DE, Hanna BD, Eilevstjonn J, Diaz LK, Gillespie MJ, Rome JJ, Sutton RM, Berg RA, Nadkarni VM. Sternal wall pressure comparable to leaning during CPR impacts intrathoracic pressure and haemodynamics in anaesthetized children during cardiac catheterization. Resuscitation 2013;84:1674-1679.

Guidelines for cardiopulmonary resuscitation and emergency cardiac care. Emergency Cardiac Care Committee and Subcommittees, American Heart Association. Part II. Adult basic life support. JAMA 1992; 268:2184-2198.

Hellevuo H, Sainio M, Nevalainen R, Huhtala H, Olkkola KT, Tenhunen J, Hoppu S. Deeper chest compression - more complications for cardiac arrest patients? Resuscitation 2013;84:760-765.
Hostler D, Everson-Stewart S, Rea TD, Stiell IG, Callaway CW, Kudenchuk PJ, Sears GK, Emerson SS, Nichol G; Resuscitation Outcomes Consortium Investigators. Effect of real-time feedback during cardiopulmonary resuscitation outside hospital: prospective, cluster-randomised trial. BMJ 2011;342:d512.

Idris AH, Guffey D, Aufderheide TP, Brown S, Morrison LJ, Nichols P, Powell J, Daya M, Bigham BL, Atkins DL, Berg R, Davis D, Stiell I, Sopko G, Nichol G; Resuscitation Outcomes Consortium (ROC) Investigators. Relationship between chest compression rates and outcomes from cardiac arrest. Circulation 2012;125:3004-3012.

Marijon E, Tafflet M, Celermajer DS, Dumas F, Perier MC, Mustafic H, Toussaint JF, Desnos M, Rieu M, Benameur N, Le Heuzey JY, Empana JP, Jouven X. Sports-related sudden death in the general population. Circulation 2011;124:672-681.

O'Connor GT, Buring JE, Yusuf S, Goldhaber SZ, Olmstead EM, Paffenbarger RS Jr, Hennekens CH. An overview of randomized trials of rehabilitation with exercise after myocardial infarction. Circulation 1989; 80:234-244.

Oldridge NB, Guyatt GH, Fischer ME, Rimm AA. Cardiac rehabilitation after myocardial infarction. Combined experience of randomized clinical trials. JAMA 1988;260:945-950.

Paffenbarger RS Jr, Hyde RT, Wing AL, Lee IM, Jung DL, Kampert JB. The association of changes in physical-activity level and other lifestyle characteristics with mortality among men. N Engl J Med 1993;328:538545.

Rea TD, Page RL. Community approaches to improve resuscitation after out-of-hospital sudden cardiac arrest. Circulation 2010;121:1134-1140.

Siscovick DS, Weiss NS, Fletcher RH, Lasky T. The incidence of primary cardiac arrest during vigorous exercise. N Engl J Med 1984;311:874877.

Stiell I, Nichol G, Wells G, De Maio V, Nesbitt L, Blackburn J, Spaite D; OPALS Study Group. Health-related quality of life is better for cardiac arrest survivors who received citizen cardiopulmonary resuscitation. Circulation 2003;108:1939-1944.

Stiell IG, Brown SP, Christenson J, Cheskes S, Nichol G, Powell J, Bigham B, Morrison LJ, Larsen J, Hess E, Vaillancourt C, Davis DP, Callaway CW; Resuscitation Outcomes Consortium (ROC) Investigators. What is the role of chest compression depth during out-of-hospital cardiac arrest resuscitation? Crit Care Med 2012;40:1192-1198.

Stiell IG, Brown SP, Nichol G, Cheskes S, Vaillancourt C, Callaway CW, Morrison LJ, Christenson J, Aufderheide TP, Davis DP, Free C, Hostler D, Stouffer JA, Idris AH; Resuscitation Outcomes Consortium Investigators. What is the optimal chest compression depth during out-of-hospital cardiac arrest resuscitation of adult patients? Circulation 2014;130:1962-1970. 
Vadeboncoeur T, Stolz U, Panchal A, Silver A, Venuti M, Tobin J, Smith G, Nunez M, Karamooz M, Spaite D, Bobrow B. Chest compression depth and survival in out-of-hospital cardiac arrest. Resuscitation 2014;85: 182-188.

Wik L, Hansen TB, Fylling F, Steen T, Vaagenes P, Auestad BH, Steen PA. Delaying defibrillation to give basic cardiopulmonary resuscitation to patients with out-of-hospital ventricular fibrillation: a randomized trial. JAMA 2003;289:1389-1395.

Yannopoulos D, McKnite S, Aufderheide TP, Sigurdsson G, Pirrallo RG,
Benditt D, Lurie KG. Effects of incomplete chest wall decompression during cardiopulmonary resuscitation on coronary and cerebral perfusion pressures in a porcine model of cardiac arrest. Resuscitation 2005;64:363-372.

Zuercher M, Hilwig RW, Ranger-Moore J, Nysaether J, Nadkarni VM, Berg MD, Kern KB, Sutton R, Berg RA. Leaning during chest compressions impairs cardiac output and left ventricular myocardial blood flow in piglet cardiac arrest. Crit Care Med 2010;38:1141-1146. 